\title{
Lo más fresco de la Florida: Calabacines (de Verano) ${ }^{1}$
}

Claudia Peñuela $^{2}$

\section{Datos nutricionales}

\section{Los calabacines de Florida son:}

$\checkmark$ Altos en vitamina $C$. La vitamina $C$ ayuda a curar las cortadas, heridas y a

mantener saludables los dientes y encías.

$\checkmark$ Altos en vitamina A cuando se come la cáscara. La vitamina A ayuda a mantener una visión normal, una piel saludable y a proteger contra las infecciones.

$\checkmark$ Buena fuente de vitamina $B_{6}$, la cual nos ayuda a metabolizar las proteínas.

$\checkmark$ Fuente de folato. El folato es necesario para la formación de células sanguíneas y reducción del riesgo en las mujeres embarazadas de tener un niño con defectos cerebrales o espina bífida.

$\checkmark$ Fuente de potasio, el cual ayuda a controlar la presión arterial.

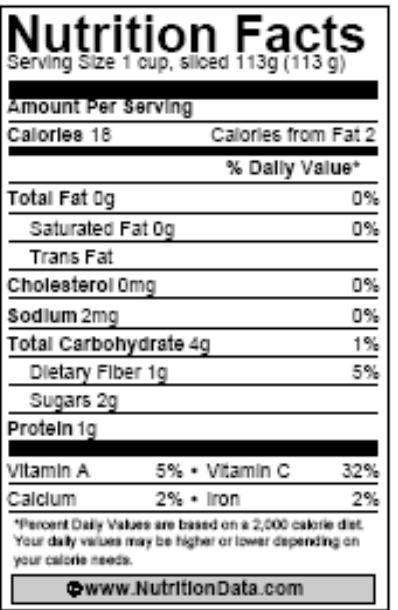
$\checkmark$ Naturalmente libres de grasa, colesterol y bajos en sodio.

Nota: Las calabazas se dividen según se produzcan en verano o en invierno. En Florida se producen calabacines de verano que incluyen el zucchini (parte de la familia de los calabacines) y el calabacín amarillo.

\section{¿Por qué comprar localmente?}

El Departamento de Agricultura de los Estados Unidos (USDA, por sus siglas en inglés) estima que el promedio de viaje de los productos agrícolas desde su origen hasta los mercados locales del agricultor es de solo $\mathbf{5 0}$ millas, comparado con $\mathbf{2 , 0 0 0}$ millas hasta los supermercados.

Compre localmente y obtenga estos beneficios:

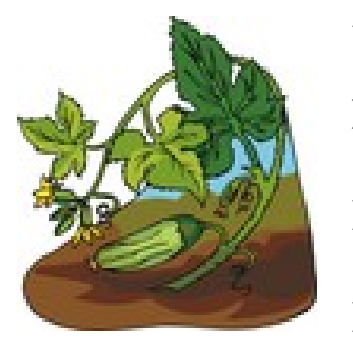

Frescura y nutrición. Las frutas y verduras cosechadas en su punto tienen mejor sabor y características nutricionales.

Social/cultural. Ayuda a la comunidad a estar consciente de la importancia de la agricultura.

Ambiental. Protege los recursos naturales como espacios verdes, fauna, flora, agua, aire y suelos.

Económico. Promueve la fuerza laboral local.

1. Este documento, FCS8880-Span, es uno de una serie del Departamento de Ciencias de la Familia, la Juventud y la Comunidad, Servicio de Extensión Cooperativa de la Florida, Instituto de Alimentos y Ciencias Agrícolas, Universidad de la Florida. Fecha primera publicación: agosto, 2009. Visite nuestro sitio web EDIS en http://edis.ifas.ufl.edu.

2. Claudia Peñuela, asistente en nutrición-EFNEP, Departamento de Ciencias de la Familia, la Juventud y la Comunidad, Servicio de Extensión Cooperativa, Instituto de Alimentos y Ciencias Agrícolas, Universidad de la Florida, Gainesville, Florida 32611. información educativa y otros servicios, ú nicamente a los individuos e i nstituciones que operan sin discriminación alguna con relación a la raza, credo, color, religión, edad, incapacidad, sexo, orientación sexual, estado civil, nacionalidad, opinión política o afiliaciones. El Departamento de Agricultura de los Estados Unidos, Servicio de Extensión Cooperativa, Universidad de la Florida, IFAS, Florida A. \& M. Programa de Extensión Cooperativa y Juntas de Comisionados del Condado en la cooperación. Millie Ferrer-Chancy, Decana Interina. 


\section{¿Dónde se cosechan los calabacines de Florida?}

La mayoría del zucchini crece en el norte y centro de Florida. Mientras que el calabacín amarillo crece en el centro oeste y sur de Florida. Los calabacines de verano se adaptan bien al clima templado. Se deben cosechar antes de que hayan madurado totalmente.

\section{¿Cuándo puede comprar calabacines en Florida?}

Puede comprar calabacines desde septiembre hasta junio. ¡Durante diez meses del año!

\section{Seleccione}

\begin{tabular}{|l|l|l|l|l|l|l|l|l|l|l|l|}
\hline ENE & FEB & MAR & ABR & MAY & JUN & JUL & AGO & SEP & OCT & NOV & DIC \\
\hline
\end{tabular}

$\checkmark$ Zucchini verde intenso brillante, delgado y de forma cilíndrica.

$\checkmark$ Calacacines amarillos con su color brillante y de forma cilíndrica o de botella.

$\checkmark$ Calabacines de verano tiernos, firmes y sin puntos blandos.

$\checkmark$ Calabacines de verano pesados para su tamaño.

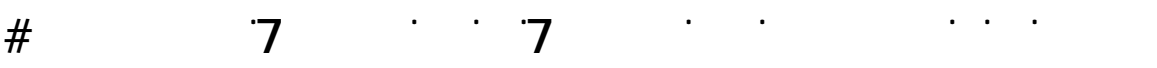

calabacines de colores con tomate gratinados

\section{Rinde: 6 Porciones}

2 dientes de ajo, picados

2 cebollas puerro, picadas

1 cucharada de albahaca picada, o 1

cucharadita de albahaca seca

$1 / 2$ cdta de sal y $1 / 2$ cdta de pimienta negra

2 calabacines amarillos, rebanados a lo largo

2 zucchini, rebanados a lo largo

3 tomates, rebanados finamente

2 cucharadas de queso Parmesano rallado

$1 / 4$ taza de migas de pan

Aceite de oliva para rociar
1. Precaliente el horno a $400^{\circ} \mathrm{F}$. Ligeramente unte con aceite una bandeja para hornear de 8-pulgadas.

2. Esparza el ajo, la cebolla puerro y la albahaca en la base de la bandeja. Añada sal y pimienta.

3. Rebane los calabacines amarillos, zucchini y tomate. Coloque capas de cada verdura alternadas hasta llenar toda la bandeja.

4. Esparza queso por encima, luego migas de pan. Rocíe un poco de aceite de oliva.

5. Hornee por 20 a 25 minutos, hasta que las verduras estén tiernas. Deje reposar por 5 minutos antes de servir.

Información nutricional por porción: Calorías 95 cal; Grasa Total 2g; Colesterol 2mg; Sodio 266mg; Carbohidratos 18g; Proteína 6g. Buena fuente de vitamina $A$ y $C$.

Adaptado de: http://www.florida-agriculture.com/pubs/pubform/pdf/The Florida Chef Flavorful Seasons Cookbook.pdf

\section{Zucchíni sofreído}

1 cucharada de aceite vegetal

1 cebolla mediana

1 calabacín amarillo mediano

1 zucchini mediano

1 pimentón rojo mediano

$1 / 2$ cucharadita de pimienta negra

$1 / 4$ cucharadita de albahaca

$1 / 4$ cucharadita de orégano

\section{Rinde: 4 Porciones}

1. Pele la cebolla. Córtela en rebanadas delgadas.

2. Rebane de forma delgada los calabacines.

3. Pique finamente el pimentón rojo.

4. Caliente el aceite en el sartén. Añada las rebanadas de cebolla, cocine a fuego medio por 1 minuto.

5. Añada las especias y sofríalas revolviendo constantemente.

6. Cocine por 3 a 5 minutos hasta que las verduras estén tiernas

Información nutricional por porción: Calorías 70 cal; Grasa Total 3.5g; Colesterol 0mg; Sodio 15mg; Carbohidratos 8g; Proteína 2g. Buena fuente de vitamina C.

Adaptado de: Pennsylvania Nutrition Education Network, Website Recipes, The Pennsylvania Nutrition Education Program; y http://recipefinder.nal.usda.gov/index.php?mode=display\&rec id $=464$ 